\title{
Outpatient primary and tertiary healthcare utilisation among public rental housing residents in Singapore
}

\author{
Jun Jie Benjamin Seng ${ }^{1 \dagger}$, Vanessa Zi Kun Lim ${ }^{1 \dagger}$, Yu Heng Kwan², Julian Thumboo $3,4,5$ and Lian Leng LOW ${ }^{5,6,7^{*}}$ (D)
}

\begin{abstract}
Background: Globally, public housing is utilized to provide affordable housing for low-income households. Studies have shown an association between public housing and negative health outcomes. There is paucity of data pertaining to outpatient primary and tertiary healthcare resources utilization among public rental housing residents in Singapore.

Methods: A retrospective cohort study was performed, involving patients under the care of SingHealth Regional Health System (SHRS) in Year 2012. Healthcare utilization outcomes evaluated included number of outpatient primary and specialist care clinic visits, emergency department visits and hospitalization in Year 2011. Multivariate logistical analyses were used to examine the association between public rental housing and healthcare utilization.

Results: Of 147,105 patients, 10,400 (7.1\%) patients stayed in public rental housing. There were more elderly (54.8 \pm 18.0 vs $49.8 \pm 17.1, p<0.001$ ) and male patients [5279 (50.8\%) vs 56,892 (41.6\%), $\mathrm{p}<0.001$ ] residing in public rental housing. Co-morbidities such as hypertension and hyperlipidemia were more prevalent among public rental housing patients. $(p<0.05)$.

After adjustment for covariates, public rental housing was not associated with frequent outpatient primary care clinic or specialist outpatient clinic attendances $(p>0.05)$. However, it was associated with increased number of emergency department visits (OR: 2.41, 95\% Cl: 2.12-2.74) and frequent hospitalization (OR: 1.56, 95\% Cl: 1.33-1.83).

Conclusion: Residing in public rental housing was not associated with increased utilization of outpatient healthcare resources despite patients' higher disease burden and frequency of emergency department visits and hospitalizations. Further research is required to elucidate their health seeking behaviours.
\end{abstract}

Keywords: Public rental housing, Ambulatory care, Primary healthcare utilisation, Public housing, Healthcare resources

\section{Background}

Low socio-economic status (SES) has been shown to be associated with increased risk of illnesses and comorbidities [1]. In the United States, low income and education level have been found to predict increased risk for cardiovascular disease and mortality [2]. Low SES has also been demonstrated to influence patterns of utilization of healthcare services. While some studies found that

\footnotetext{
* Correspondence: low.lian.leng@singhealth.com.sg

Benjamin Jun Jie Seng and Vanessa Zi Kun Lim are co-first authors

${ }^{5}$ SingHealth Regional Health System, Singapore Health Services, 169608,

Outram Road, Singapore, Singapore

${ }^{6}$ Department of Family Medicine and Continuing Care, Singapore General

Hospital, Outram Road Singapore, Singapore 169608, Singapore

Full list of author information is available at the end of the article
}

lower SES groups encounter difficulties with regards to healthcare access $[3,4]$, they were shown to have higher healthcare utilization in countries where universal healthcare coverage is provided for [5, 6]. A study by Dani F. et al. found that people with lower SES tended to have more frequent emergency department visits and hospital admissions.

There exist a multitude of measures for SES which include factors such as education level, household income and occupation [7]. During routine clinical care, time may not permit for obtaining these details, which results in incomplete data [6]. Additionally, these data are not comprehensively captured at a population level. Housing type, which is available from patient's home address

(C) The Author(s). 2019 Open Access This article is distributed under the terms of the Creative Commons Attribution 4.0 International License (http://creativecommons.org/licenses/by/4.0/), which permits unrestricted use, distribution, and 
and easily retrievable from electronic health records, may provide a more convenient measure of SES for physicians to screen patients.

Globally, public housing is utilized to provide affordable housing for low-income households [8, 9]. In Singapore, home ownership for majority of her 5.6 million citizens is achieved through public housing [10]. To help the lowest income ( $\leq$ USD \$1123 per month) households cope with living costs, one or two-room public flats are made available for rental from the government at heavily subsidized rates. These public rental housing flats are organized into blocks, and clusters of public rental housing blocks are located with public housing blocks of various types to promote neighbourhood social cohesion. However, studies have shown that residence in public housing is associated with negative health outcomes [11, 12]. Home ownership has been shown to have an inverse relationship with mortality [13]. In the HOPE VI panel study, public housing residents were found to have a two-fold higher likelihood of developing hypertension and hyperlipidaemia [14]. Another study showed that public housing is linked with obesity and poorer health statuses of mothers [11].

The significance of primary care and its contribution to a nation's healthcare system is becoming increasingly recognized. Primary care is defined as essential healthcare made universally accessible to individuals in the community at an affordable cost that allows a continuing healthcare process [15]. As primary care serves as the first-line of care for most patients, the extent of utilization of primary care resources often reflects the population's general health status and healthcare needs. Studies have also shown that people living in areas with more primary care physicians tend to have better health outcomes and that individuals' utilization of primary care is associated with better health [16].

In Singapore, approximately $70-80 \%$ of its overall healthcare demands are addressed by the public sector [17]. Healthcare financing in Singapore primarily comprises of government subsidies and 3 flagship programmes which are namely Medisave, Medishield Life and Medifund $[18,19]$. Every working Singaporean citizen contributes a proportion of their monthly salary to Medisave, a mandatory and government enforced medical savings account which pays for major healthcare expenditures such as hospitalization [19]. In contrast, Medishield Life is an automatically opt-in health insurance scheme which is used to subsidize high cost hospitalizations [19]. Lastly, Medifund is a means-tested social welfare program which is designed as a safety net to fund the healthcare costs of poorest citizens in the country, of which a significant proportion reside in public rental housing [19]. Therefore, out-of-pocket costs are expected to be minimal or nil for many residents living in public rental housing. A review by Chan et al. on health seeking behaviour of public rental housing residents found that they had lower participation in health screening, and preferred alternative medicine practitioners to western-trained doctors for primary care [20]. It is possible that many public rental housing residents may neglect health and primary healthcare due to conflicting life priorities, resulting in over-utilization of specialist and emergency care services at more advanced disease states.

Overall, the delivery of primary healthcare services locally is contributed by both private general practitioner (GP) clinics and public outpatient primary care clinics (polyclinics). While the majority (80\%) of primary care provided by GPs in the private sector, polyclinics in each public regional health system play an important role in management and follow-up of $80 \%$ of patients with chronic diseases [21]. For patients with medical condition requiring specialist care, they are referred to outpatient specialist clinics located in tertiary centres. Although previous studies have examined the utilization of tertiary healthcare resources such as hospital services among public rental housing residents [6], there is no study which has examined their utilization of outpatient primary and tertiary healthcare resources in Singapore.

As such, this study aims to examine the utilization of outpatient primary and tertiary healthcare resources among public rental housing patients.

\section{Methods}

A retrospective cohort study was conducted involving all adult patients who were under the medical care of SingHealth Regional Health System (SRHS) in Year 2012. Among the regional health systems in Singapore, SRHS is the largest cluster and is responsible for the provision of healthcare services to residents in SouthCentral Singapore We excluded patients who stayed in non-SRHS residential areas as they would fall under the purview of a different regional health system. Non-citizens were also excluded as the likelihood of them being under long-term medical care from SRHS is low. Approval from Singapore Health Services Centralized Institutional Review Board (CIRB 2016/2294) was obtained prior to the study's initiation.

SRHS electronic medical records were utilized to extract patients' socio-demographic and clinical details. These information included patient's age, gender, ethnicity and the type of residential housing Major co-morbidities such as diabetes mellitus, hypertension and renal disease which are listed in the Charlson and Elixhauser comorbidity index were also collected [22]. The primary outcome in this study was the number of primary care clinic visits and specialist clinic visits that each patient had in Year 2011. Secondary outcomes that were examined included the number of emergency department visits and hospital admission for each patient in the past 1 year from date of 
inclusion. In this study, frequent primary care outpatient clinic attendance and outpatient specialist clinic visits were defined by $\geq 4$ visits and $\geq 3$ visits per year respectively [6]. Frequent emergency department visits and hospital admissions were defined as $\geq 4$ visits and $\geq 3$ admissions per year respectively [6, 23-26]. The cut-offs for frequent primary care outpatient clinic visits, outpatient specialist clinic visit and hospital admissions were determined by expert consensus across the major health regional systems in Singapore [23]. The threshold of $\geq 4$ visits for emergency department visit as per a study performed by Locker et al. who found that there is $>99 \%$ of chance attenders who would presenting at the A\&E on $<4$ occasions per year as compared to a true frequent attender [24].

\section{Statistical analyses}

Statistical analyses were performed using SPSS version 23 (SPSS Inc., Chicago, IL, USA). Differences in characteristics of patients who stayed and do not stay in public rental housing were assessed using Student's t-test and Chi-square test, where appropriate. Univariate analyses were also performed to evaluate if there were differences in socio-demographic and clinical characteristics, as well as public rental housing residence status between patients with higher primary and tertiary healthcare utilization. Thereafter, variables with $p$-value $<0.05$ were entered in the multivariate logistical regression model. A two-tailed p-value of $<0.05$ was considered statistically significant.

\section{Results}

Figure 1 shows the flowchart for patient inclusion in the study. A total of 147,105 patients were included, of which $10,400(7.1 \%)$ patients stayed in public rental housing.

Table 1 details the anthropomorphic and clinical characteristics of patients who stayed in public rental flats and not in public rental flat, as well as their utilization of healthcare resources among patients. The mean age of patients was $50.2 \pm 17.2$ years old and majority of patients were female $(84,934,57.7 \%)$. Compared to patients who did not stay in public rental housing, patients who stayed in public rental housing were older $(54.8 \pm 18.0$ vs $49.8 \pm 17.1, p<0.001)$. In addition, there were more male [5279 (50.8\%) vs 56,892 (41.6\%), $\mathrm{p}<0.001$ ] but less Chinese [6367 (61.3\%) vs 109,089 (79.8\%), $\mathrm{p}<0.001$ ] patients staying in public rental flats relative to those patients not staying in public rental flats. The prevalence of most comorbidities such as diabetes, hypertension and hyperlipidemia were higher among patients staying in public rental flats $(p<0.05)$. However, there were no significant differences in the rates of hyperthyroidism, hypothyroidism, bipolar disease, anxiety as well as both non-metastatic and metastatic malignancy between the 2 groups of patients $(p>0.05)$. The attendance rates of polyclinics and hospital admissions were higher among patients who stayed in public rental housing $(p \leq 0.001)$. In contrast, patients who did not stay in public rental housing had higher number of outpatient specialist clinic visits $(2.53 \pm 5.66$ vs $2.16 \pm 5.47, p<0.001)$.

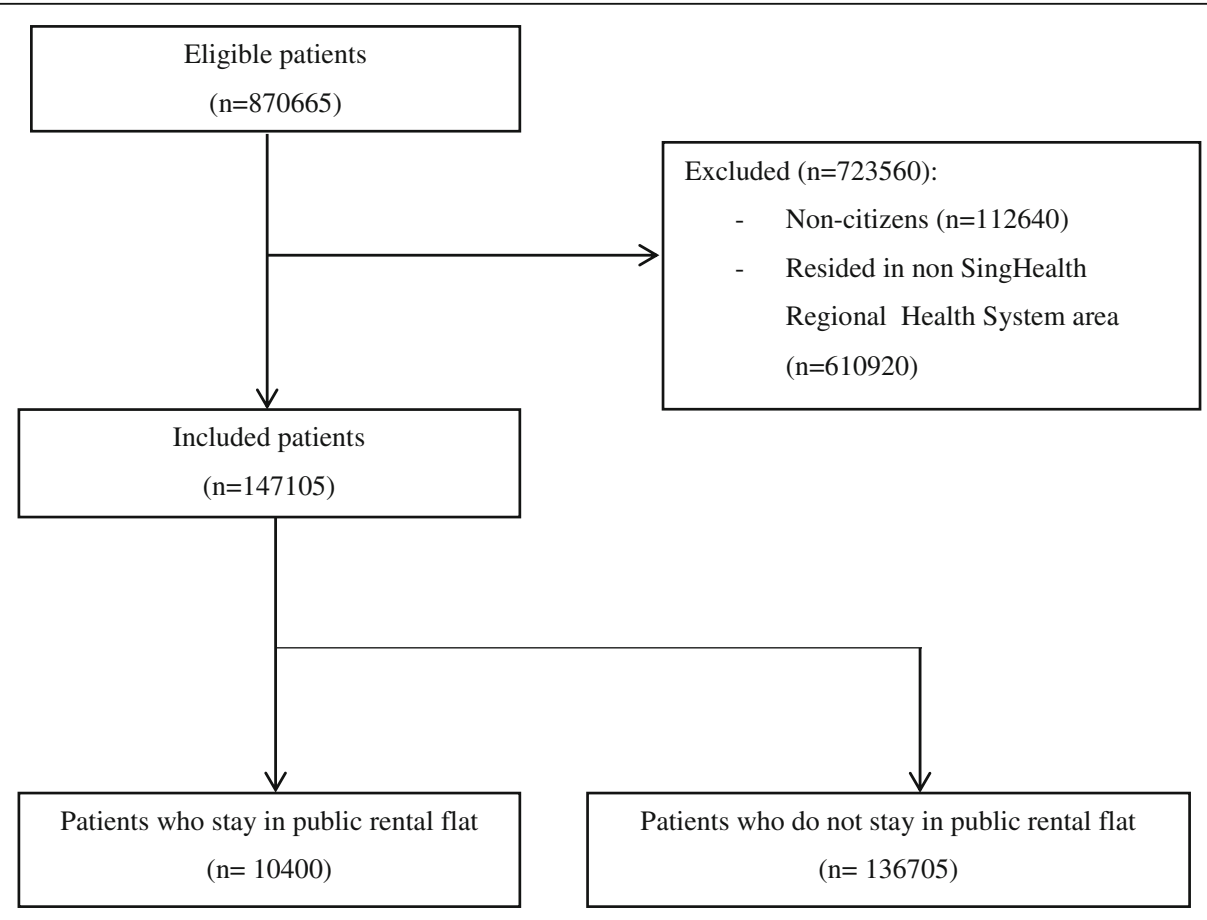

Fig. 1 Flowchart for inclusion of patients 
Table 1 Patient characteristics and their association with residence in rental flats

\begin{tabular}{|c|c|c|c|c|}
\hline & $\begin{array}{l}\text { Stayed in public rental } \\
\text { flat }(n=10,400)\end{array}$ & $\begin{array}{l}\text { Not stayed in public rental } \\
\text { flat }(n=136,705)\end{array}$ & $\begin{array}{l}\text { All } \\
(n=147,105)\end{array}$ & $\begin{array}{l}p \\
\text { value }\end{array}$ \\
\hline \multicolumn{5}{|l|}{ Patient Demographics in Year 2012} \\
\hline Age, Mean (SD) & $54.8(18.0)$ & $49.8(17.1)$ & $50.2(17.2)$ & $<0.001$ \\
\hline Gender & & & & $<0.001$ \\
\hline Female (\%) & $5121(49.2)$ & $79,813(58.4)$ & $84,934(57.7)$ & \\
\hline Male (\%) & $5279(50.8)$ & $56,892(41.6)$ & $62,171(42.3)$ & \\
\hline Ethnicity & & & & $<0.001$ \\
\hline Chinese (\%) & $6367(61.3)$ & 109,089 (79.8) & $115,456(78.5)$ & \\
\hline Indian (\%) & $1185(10.0)$ & $10,078(7.4)$ & $11,263(7.7)$ & \\
\hline Malay (\%) & $2526(24.3)$ & $12,056(8.8)$ & $14,582(9.9)$ & \\
\hline Others (\%) & $322(3.1)$ & $5482(4.0)$ & $5804(3.9)$ & \\
\hline Deaths (\%) & $1063(10.2)$ & $5659(4.1)$ & $6722(4.6)$ & $<0.001$ \\
\hline \multicolumn{5}{|l|}{ Medical Comorbidities in Year 2012} \\
\hline Diabetes without complications (\%) & $2023(19.5)$ & $18,785(13.7)$ & $20,808(14.1)$ & $<0.001$ \\
\hline Hypertension (\%) & $3983(38.3)$ & $39,074(28.6)$ & $43,057(29.3)$ & $<0.001$ \\
\hline Hyperlipidemia (\%) & $3503(33.7)$ & $38,934(28.5)$ & $42,437(28.8)$ & $<0.001$ \\
\hline Asthma (\%) & $708(6.8)$ & $4250(3.1)$ & $4958(3.4)$ & $<0.001$ \\
\hline Chronic Obstructive Pulmonary Disease (\%) & $700(6.7)$ & $2385(1.7)$ & $3085(2.1)$ & $<0.001$ \\
\hline Chronic Obstructive Pulmonary Disease with cor pulmonale (\%) & $603(5.8)$ & $1971(1.4)$ & $2574(1.7)$ & $<0.001$ \\
\hline Osteoarthritis (\%) & $1626(15.6)$ & $15,161(11.1)$ & $16,787(11.4)$ & $<0.001$ \\
\hline Hyperthyroidism (\%) & $69(0.7)$ & $1121(0.8)$ & $1190(0.8)$ & 0.086 \\
\hline Hypothyroidism (\%) & $132(1.3)$ & $1782(1.3)$ & $1914(1.3)$ & 0.766 \\
\hline Diabetes with complications (\%) & $279(2.7)$ & $1890(1.3)$ & $2169(1.5)$ & $<0.001$ \\
\hline Cerebrovascular accident (\%) & $689(6.6)$ & $4484(3.3)$ & $5173(3.5)$ & $<0.001$ \\
\hline Chronic Kidney Disease Stage 3-4 (\%) & $486(4.7)$ & $4128(3.0)$ & $4614(3.1)$ & $<0.001$ \\
\hline Chronic kidney disease stage $V$ or End-stage renal failure (\%) & $268(2.6)$ & $1539(1.8)$ & $1807(1.2)$ & $<0.001$ \\
\hline Depression (\%) & $401(3.9)$ & $2409(1.8)$ & $2810(1.9)$ & $<0.001$ \\
\hline Schizophrenia (\%) & $151(1.5)$ & $410(0.3)$ & $561(0.4)$ & $<0.001$ \\
\hline Dementia (\%) & $63(0.6)$ & $450(0.3)$ & $513(0.3)$ & $<0.001$ \\
\hline Bipolar disease (\%) & $2(0.02)$ & $30(0.02)$ & $32(0.02)$ & 0.856 \\
\hline Anxiety (\%) & $102(0.8)$ & $1188(0.9)$ & $1290(0.9)$ & 0.239 \\
\hline Collagen vascular disease (\%) & $67(1.0)$ & $450(0.3)$ & $517(0.4)$ & $<0.001$ \\
\hline Parkinson disease (\%) & $50(0.5)$ & $431(0.3)$ & $481(0.3)$ & 0.004 \\
\hline Epilepsy (\%) & $127(1.2)$ & $588(0.4)$ & $715(0.5)$ & $<0.001$ \\
\hline Coronary heart disease (\%) & $1047(10.1)$ & $8462(6.2)$ & $9509(6.5)$ & $<0.001$ \\
\hline Atrial fibrillation (\%) & $150(1.4)$ & $1136(0.8)$ & $1286(0.9)$ & $<0.001$ \\
\hline Heart failure (\%) & $379(3.6)$ & $1187(0.9)$ & $2196(1.5)$ & $<0.001$ \\
\hline Peripheral vascular disease (\%) & $161(1.6)$ & $963(0.7)$ & $1124(0.8)$ & $<0.001$ \\
\hline Hip fracture (\%) & $53(0.5)$ & $226(0.2)$ & $279(0.2)$ & $<0.001$ \\
\hline Spine fracture (\%) & $71(0.7)$ & $381(0.3)$ & $452(0.3)$ & $<0.001$ \\
\hline Chronic liver disease (\%) & $137(1.3)$ & $937(0.7)$ & $1074(0.7)$ & $<0.001$ \\
\hline Pressure ulcer (\%) & $39(0.4)$ & $204(0.2)$ & $243(0.2)$ & $<0.001$ \\
\hline Non-metastatic malignancy (\%) & $365(3.5)$ & 4519 (3.3) & $4884(3.3)$ & 0.268 \\
\hline Metastatic malignancy (\%) & $73(0.7)$ & $770(0.6)$ & $843(0.6)$ & 0.071 \\
\hline
\end{tabular}


Table 1 Patient characteristics and their association with residence in rental flats (Continued)

\begin{tabular}{|c|c|c|c|c|}
\hline & $\begin{array}{l}\text { Stayed in public rental } \\
\text { flat }(n=10,400)\end{array}$ & $\begin{array}{l}\text { Not stayed in public rental } \\
\text { flat }(n=136,705)\end{array}$ & $\begin{array}{l}\text { All } \\
(n=147,105)\end{array}$ & $\begin{array}{l}P \\
\text { value } \\
\end{array}$ \\
\hline \multicolumn{5}{|c|}{ Past 1-year Healthcare Utilization in 2011} \\
\hline \multicolumn{5}{|l|}{ Polyclinic attendances } \\
\hline Number of visits, mean (SD) & $3.12(6.02)$ & $2.40(3.98)$ & $2.45(4.16)$ & 0.001 \\
\hline \multicolumn{5}{|c|}{ Specialist outpatient clinic attendances } \\
\hline Number of visits, mean (SD) & $2.16(5.47)$ & $2.53(5.66)$ & $2.50(5.65)$ & $<0.001$ \\
\hline \multicolumn{5}{|l|}{ Emergency department attendances } \\
\hline Number of visits, mean (SD) & $0.43(1.67)$ & $0.13(0.58)$ & $0.15(0.72)$ & $<0.001$ \\
\hline \multicolumn{5}{|l|}{ Hospital admissions } \\
\hline Number of visits, mean (SD) & $0.26(1.00)$ & $0.11(0.49)$ & $0.12(0.54)$ & $<0.001$ \\
\hline
\end{tabular}

Results for the univariate analyses for differences in characteristics of patients with more and less frequent primary care outpatient clinic, outpatient specialist clinic, emergency department visits and hospital admissions were reported in Additional files 1,2,3 and 4: Annexes A, B, C and D respectively in more detail (See Additional files 1,2,3 and 4: Annexes A, B, C, D).

Table 2 shows the results of multivariate analyses of public rental housing on healthcare utilization. After adjustment for socio-demographic and clinical covariates, public rental housing was associated with increased emergency department visits (OR: 2.41, 95\% CI: 2.12-2.74) and frequent hospitalization (OR: 1.56, 95\% CI: 1.33-1.83) but lower utilization of specialist outpatient clinics (OR: 0.83, 95\% CI: 0.79-0.87). However, public rental housing was not associated with frequent outpatient primary care clinic attendances (OR: 1.048, 95\% CI: 0.993-1.107).

\section{Discussion}

In this study, residence in public rental housing was not associated with increased utilization of outpatient primary and tertiary healthcare resources despite their higher disease burden, increased number of emergency department and hospital admissions.
Studies examining primary care utilization by SES generally showed mixed results, where equitable distribution was observed across SES groups in some studies while other studies found increased usage of primary care services among low SES groups [27-29]. Increased primary healthcare utilization has been linked to better health outcomes [16] and it remains unclear if patients residing in public rental housing are utilizing primary healthcare resources optimally. This is especially of concern as they were found to have higher number of hospital admissions and emergency department visits.

Research has shown that there are many barriers to primary healthcare services utilization among lower SES groups. These barriers can largely be divided into categories which are namely population characteristics, patients' cultural norms and values as well as healthcare system related services [30]. One of the cultural reasons that may compromise utilization of primary healthcare services is the perceived superiority of alternative medicine. A study showed that Western medicine were less preferred among lower income patients seeking primary healthcare, with only $11.1 \%$ preferring Western-trained physicians while 52.6 and $29.5 \%$ of patients prefer alternative medicine and self-reliance respectively [31]. The strong belief in self-reliance reflects a mindset that

Table 2 The impact of residing in public rental housing on hospital emergency utilization, outpatient primary care clinic, specialist outpatient clinic attendances and hospital admission in Year 2011

\begin{tabular}{lll}
\hline Outcomes & Residing in public rental housing OR (95\% Cl) & p-value \\
\hline Frequent outpatient primary care clinic attendances (4 or more) & $1.05(0.99-1.11)$ & 0.090 \\
Frequent specialist outpatient clinic attendances & $0.83(0.79-0.87)$ & $<0.001$ \\
Frequent ED visits (3 or more) & $2.41(2.12-2.74)$ & $<0.001$ \\
Frequent hospital admission (3 or more) & $1.56(1.33-1.83)$ & $<0.001$
\end{tabular}

Adjusted for Age, Gender, Ethnicity, Number of hospital admission, Specialist outpatient clinic visits, Emergency department visits (1 year before index admission), History of malignancy, Diabetes without complications, Hypertension, Hyperlipidemia, Chronic Kidney Disease Stage 3-4, Asthma, Chronic Obstructive Pulmonary Disease, Chronic Obstructive Pulmonary Disease with cor pulmonale, Osteoarthritis, Diabetes with complications, Cerebrovascular accident, Chronic kidney disease stage V or End-stage renal failure, Depression, Schizophrenia, Dementia, Collagen vascular disease, Parkinson disease, Epilepsy, Coronary heart disease, Atrial fibrillation, Heart failure, Peripheral vascular disease, Hip fracture, Spine fracture, Chronic liver disease, Pressure ulcer, Non-metastatic malignancy, Metastatic malignancy 
illnesses can get better without professional help and could impede early detection and treatment of diseases. Other patient and cultural related factors which may contribute to their low primary healthcare utilization includes misconception about health and financial costs $[29,32]$. A study conducted among public rental housing residents found that they were more likely to seek medical attention only when symptoms such as pain manifest [33]. Another commonly cited health-system related reason suggested include lack of access to healthcare and long clinic waiting time [34]. It is noteworthy that a study by the English National Health Services found a 43-day difference in waiting time for non-coronary revascularization procedure between patients with different SES [35]. Locally, barriers that public rental housing residents commonly face for subsidized specialist care include the need to obtain referral letters from primary care physicians in public healthcare facilities and long waiting time, which can span up to three to six months [36].

It was interesting to note that public rental housing patients had lower utilization of specialist outpatient clinics. This was similar to findings from other studies that showed lower utilization of specialist visits in low SES groups compared to higher SES groups [5, 37]. A potential reason for this could be due to patients' non-compliance with follow-up at SOCs. In contrast to primary care where services are typically provided within fixed-length appointment slots, specialists' appointment lengths are highly variable and diagnosis-dependent, which may result in variable waiting times and inconvenience to patients [38]. Strong social support has also been shown to increase the probability of physician visits [39]. Although the level of social support among public rental housing residents was not assessed in this study, the lack of social support among public rental housing residents may potentially reduce their adherence to specialist outpatient clinic visits, especially among patients with ambulatory problems and should be explored in future studies.

The pattern of outpatient primary and tertiary outpatient healthcare utilization observed in this study could potentially be attributed to the heterogeneity in the health statuses and comorbidities of patients. With the paradigm shift towards greater efficiency for healthcare delivery, healthcare delivery targeted at groups of patients with similar pattern of healthcare utilization has been proposed [40]. Population segmentation via expert-driven and data-driven approaches has been suggested to identify healthcare needs of different patient groups. A local study that performed cluster analyses on a general population found that subjects could be segmented into 5 distinct clusters of patients with varying healthcare utilization and co-morbidities [41]. Future studies may wish to consider using population segmentation approaches to identify sub-groups of public rental housing patients which have overutilization or under-utilization of healthcare resources and poor health-related outcomes. This will aid the design of appropriate healthcare interventions to improve their health-related outcomes.

Pertaining to co-morbidities, public rental housing residents were found to have higher rates of co-morbidities such as depression and diabetes. Potential reasons for these findings could be due to circumstances surrounding their housing environment. Rental housing residents are often subjected to poorer housing conditions, where environmental hazards and poor hygiene may precipitate other illnesses [42]. Research has also shown that stressful life events are associated with heart disease, diabetes, major depression and other diseases [1]. Psychological stress comes about when an individual perceives tasks and demands to be exceeding his or her ability to cope [43]. Patients in low SES groups are at risk of higher psychological stress due to increased exposure to such stressors such as financial stress of supporting a family, poor social support and discrimination [7, 42, 44]. Metabolic diseases such as diabetes are commonly affected by diet and lifestyle choices. Individuals with lower SES have been shown to be less informed about implementing lifestyle changes in aspects of smoking, exercise and diet, as compared to their higher SES peers [1].

Overall, the higher disease burden among patients staying in public rental housing, coupled with their potential underutilization of outpatient primary and tertiary healthcare resources may explain their increased frequency of emergency department visits and hospitalizations. Further studies should be performed to understand the healthcare needs for patients residing in public rental housing as well as their health-seeking behaviours and attitudes to optimize their health-related outcomes.

This study is not without limitations. Firstly, data analysed in this study only included variables that were routinely collected from electronic databases within SHRS. Consequently, other measures of primary healthcare utilization such as healthcare related costs, health insurance claims and visits to private GP clinics could not be evaluated. Future studies may look into evaluating these measures as well as other socio-demographic characteristics (e.g. household income levels, marital status, family structure and support), attitudes and beliefs (e.g. self-reliant attitude, preference for alternative medicine) and barriers in knowledge (e.g. lack of access to information, misconceptions which may affect their healthcare utilization. Secondly, data pertaining to residents utilizing healthcare facilities in other regional health systems and non-users of the SRHS was unavailable, which may affect the representativeness of the reported population. However, it is expected that the proportion of residents utilizing facilities in other 
health systems to be small due to the geographical ease of access to the primary care facilities and specialist centres available in the SHRS. Lastly, a causal association between public rental housing and primary healthcare utilization could not be established due to the retrospective nature of the study.

\section{Conclusion}

In this study, residing in public rental housing was not associated with increased utilization of outpatient primary and tertiary healthcare resources despite their higher disease burden and frequency of emergency department visits and hospitalizations. Further research is required to elucidate and understand health seeking behaviours among public-rental housing patients so as to optimize their appropriate utilization of outpatient primary and tertiary healthcare resources and improve their healthrelated outcomes.

\section{Additional files}

Additional file 1: Annex A. Patient characteristics and their association with outpatient primary care clinic attendances. Annex A shows the univariate analyses results for differences in characteristics of frequent and non-frequent users of outpatient primary care clinics. (DOCX $17 \mathrm{~kb}$ )

Additional file 2: Annex B. Patient characteristics and their association with specialist outpatient clinic attendances. Annex B shows the univariate analyses results for differences in characteristics of frequent and non-frequent users of specialist outpatient clinics. (DOCX 17 kb)

Additional file 3: Annex C. Patient characteristics and their association with Emergency Department visits. Annex C shows the univariate analyses results for differences in characteristics of frequent and non-frequent users of emergency department. (DOCX $17 \mathrm{~kb}$ )

Additional file 4: Annex D. Patient characteristics and their association with frequent hospital admissions. Annex D shows the univariate analyses results for differences in characteristics of patients with frequent and non-frequent hospital admissions (DOCX 17 kb)

\section{Abbreviations}

Cl: Confidence interval; CIRB: Centralized Institutional Review Board; ED: Emergency department; GP: General practitioner; OR: Odds ratio; SD: Standard deviation; SES: Socioeconomic status; SHRS: SingHealth Regional Health System; SOC: Specialist outpatient clinic; USD: United States Dollar

\section{Acknowledgements}

We would like to thank Tan Wee Boon from Academic Clinical Program for Medicine, Singapore General Hospital for the help rendered pertaining to statistical analyses in this study.

\section{Funding}

This research received grant funding from SingHealth Foundation Health Services Research (Aging) Start-up Grant SHF/HSRAg004/2015 and SingHealth Nurturing Clinician Scientist Award Academic Clinical Programme Funding FY 2016 Cycle 2. The funding sources had no role in study design, data collection and analysis, decision to publish, or preparation of the manuscript.

\section{Availability of data and materials}

The datasets generated and/or analysed during the current study are not publicly available due to institutional restrictions but are available from the corresponding author on reasonable request.

\section{Authors' contributions}

LLL was the study's principal investigator and was responsible for the conception and design of the study. SJJB, LZKV, YHK and JT were the coinvestigators. All authors contributed to the interpretation of data and literature review. SJJB and LZKV prepared the initial draft of the manuscript. All authors read and approved the final manuscript.

\section{Ethics approval and consent to participate}

Approval from Singapore Health Services Centralized Institutional Review Board (CIRB reference number: 2016/2294) was obtained prior to commencement of study. Waiver of consent was obtained and approved by the committee for this study. Permission was also obtained from the hospitals and polyclinics for access to de-identified data from patient medical records.

\section{Consent for publication}

Not applicable.

\section{Competing interests}

The authors declare that they have no competing interests.

\section{Publisher's Note}

Springer Nature remains neutral with regard to jurisdictional claims in published maps and institutional affiliations.

\section{Author details}

${ }^{1}$ Duke-NUS Medical School, 8 College Road, Singapore 169857, Singapore. ${ }^{2}$ Program in Health Services and Systems Research, Duke-NUS Medical School, 8 College Road, Singapore 169857, Singapore. ${ }^{3}$ Health Services Research Centre, Singapore Health Services, Outram Road, Singapore 169608, Singapore. ${ }^{4}$ Department of Rheumatology and Immunology, Singapore General Hospital, Outram Road, Singapore 169608, Singapore. ${ }^{5}$ Sing Health Regional Health System, Singapore Health Services, 169608, Outram Road, Singapore, Singapore. 'Department of Family Medicine and Continuing Care, Singapore General Hospital, Outram Road Singapore, Singapore 169608, Singapore. ${ }^{7}$ Sing Health Duke-NUS Family Medicine Academic Clinical Program, Outram Road, Singapore 169608, Singapore.

Received: 25 September 2018 Accepted: 27 March 2019

Published online: 15 April 2019

\section{References}

1. Link BG, Phelan J. Social conditions as fundamental causes of disease. J Health Soc Behav. 1995:80-94. https://www.jstor.org/stable/2626958?seq= 1\#page_scan_tab_contents

2. Shea S, Lima J, Diez-Roux A, Jorgensen NW, McClelland RL. Socioeconomic status and poor health outcome at 10 years of follow-up in the multi-ethnic study of atherosclerosis. PLoS One. 2016;11(11):e0165651.

3. Garrido-Cumbrera $M$, Borrell $C$, Palència $L$, et al. Social class inequalities in the utilization of health care and preventive services in Spain, a country with a national health system. Int J Health Serv. 2010;40(3):525-42.

4. Habicht J, Kiivet R-A, Habicht T, Kunst AE. Social inequalities in the use of health care services after 8 years of health care reforms-a comparative study of the Baltic countries. Int J Public Health. 2009;54(4):250-9.

5. Filc D, Davidovich N, Novack L, Balicer RD. Is socioeconomic status associated with utilization of health care services in a single-payer universal health care system? Int J Equity Health. 2014;13:115. https://www.ncbi.nlm. nih.gov/pmc/articles/PMC4260253/

6. Low LL, Wah W, Ng MJ, Tan SY, Liu N, Lee KH. Housing as a social determinant of health in Singapore and its association with readmission risk and increased utilization of hospital services. Front Public Health. 2016;4:109.

7. Shavers VL. Measurement of socioeconomic status in health disparities research. J Natl Med Assoc. 2007;99(9):1013.

8. Housing and Development Board. Annual report 2007/2008. Singapore: Housing and Development Board; 2008.

9. Housing and Developement Board. Annual report 2007/2008. Singapore: Housing and Development Board; 2008.

10. Braveman P, Gottlieb L. The social determinants of health: It's time to consider the causes of the causes. Public Health Rep. 2014;129(Suppl 2):19-31.

11. Fertig AR, Reingold DA. Public housing, health, and health behaviors: is there a connection? J Policy Anal Manage. 2007;26(4):831-60. 
12. Seng JJB, Kwan YH, Goh H, Thumboo J, Low LL. Public rental housing and its association with mortality - a retrospective, cohort study. BMC Public Health. 2018;18(1):665.

13. Ferri $C P, A$ costa $D$, Guerra $M$, et al. Socioeconomic factors and all cause and cause-specific mortality among older people in Latin America, India, and China: a population-based cohort study. PLoS Med. 2012;9(2):e1001179.

14. Regidor E. Social determinants of health: a veil that hides socioeconomic position and its relation with health. J Epidemiol Community Health. 2006;60(10):896-901.

15. Starfield B. Primary care: balancing health needs, services, and technology. Religion in America; 1998.

16. Starfield B, Shi L, Macinko J. Contribution of primary care to health systems and health. Milbank Q. 2005;83(3):457-502.

17. Ministry of Health S. Admissions And Outpatient Attendances. In. Singapore 2018.

18. Gusmano MK. Healthcare financing in Singapore. In: A Singapore bioethics casebook, vol. 2. Singapore: National University of Singapore; 2017.

19. Ministry of Health S. Healthcare Schemes and Subsidies. In. Singapore 2018.

20. Chan $\mathrm{CQH}$, Lee KH, Low LL. A systematic review of health status, health seeking behaviour and healthcare utilisation of low socioeconomic status populations in urban Singapore. Int J Equity Health. 2018;17(1):39.

21. Emmanuel SC, Phua HP, Cheong PY. 2001 survey on primary medical care in Singapore. Singap Med J. 2004;45(5):199-213.

22. Quan H, Li B, Saunders D, et al. Assessing validity of ICD-9-CM and ICD-10 adminsitrative data in recording clinical conditions in a unique dually coded database. Health Serv Res. 2008;43(4):1424-41. https://www.ncbi.nIm.nih. gov/pubmed/18756617

23. Saxena N, You AX, Zhu Z, et al. Singapore's regional health systems-a datadriven perspective on frequent admitters and cross utilization of healthcare services in three systems. Int J Health Plann Manag. 2017;32(1):36-49.

24. Locker TE, Baston S, Mason SM, Nicholl J. Defining frequent use of an urban emergency department. Emerg Med J. 2007;24(6):398-401.

25. Low LL, Liu N, Wang S, Thumboo J, Ong ME, Lee KH. Predicting frequent hospital admission risk in Singapore: a retrospective cohort study to investigate the impact of comorbidities, acute illness burden and social determinants of health. BMJ Open. 2016;6(10):e012705.

26. Low LL, Tay WY, Ng MJ, Tan SY, Liu N, Lee KH. Frequent hospital admissions in Singapore: clinical risk factors and impact of socioeconomic status. Singap Med J. 2018;59(1):39-43.

27. Mclsaac W, Goel V, Naylor D. Socio-economic status and visits to physicians by adults in Ontario, Canada. J Health Serv Res Policy. 1997;2(2):94-102.

28. Morris S, Sutton M, Gravelle H. Inequity and inequality in the use of health care in England: an empirical investigation. Soc Sci Med. 2005;60(6):1251-66.

29. Shadmi E, Balicer RD, Kinder K, Abrams C, Weiner JP. Assessing socioeconomic health care utilization inequity in Israel: impact of alternative approaches to morbidity adjustment. BMC Public Health. 2011;11:609.

30. Paduch A, Kuske S, Schiereck T, et al. Psychosocial barriers to healthcare use among individuals with diabetes mellitus: a systematic review. Prim Care Diabetes. 2017;11(6):495-514

31. Wee LE, Lim LY, Shen $T$, et al. Choice of primary health care source in an urbanized low-income community in Singapore: a mixed-methods study. Fam Pract. 2014;31(1):81-91.

32. Wee LE, Koh GC. The effect of neighborhood, socioeconomic status and a community-based program on multi-disease health screening in an Asian population: a controlled intervention study. Prev Med. 2011;53(1-2):64-9.

33. Wee LE, Sin D, Cher WQ et al. "I'm healthy, I don't have pain"- health screening participation and its association with chronic pain in a low socioeconomic status Singaporean population. Korean J Pain. 2017;30(1):34-43.

34. Nunes BP, Thume E, Tomasi E, Duro SM, Facchini LA. Socioeconomic inequalities in the access to and quality of health care services. Rev Saude Publica. 2014;48(6):968-76.

35. Moscelli G, Siciliani L, Gutacker N, Cookson R. Socioeconomic inequality of access to healthcare: does choice explain the gradient? J Health Econ. 2018:57:290-314.

36. Ministry of Health S. Waiting times for new appointments at specialist outpatient clinics - cardiology. In: 2018.

37. Dunlop S, Coyte PC, Mclsaac W. Socio-economic status and the utilisation of physicians' services: results from the Canadian National Population Health Survey. Soc Sci Med. 2000;51(1):123-33.

38. Gupta D, Denton B. Appointment scheduling in health care: challenges and opportunities. IIE Trans. 2008:40(9):800-19.

39. Salinas-Rodríquez A, Moreno-Tamayo K, Hernández-Serrato M, EnríquezRosas MR, Manrique-Espinoza BS. Multidimensional social support is associated with healthcare utilization among older Mexican adults. Eur J Ageing. 2018:15(1):77-85.

40. Kiesler DJ, Auerbach SM. Optimal matches of patient preferences for information, decision-making and interpersonal behavior: evidence, models and interventions. Patient Educ Couns. 2006;61(3):319-41.

41. Low LL, Kwan YH, Liu N, Jing X, Low ECT, Thumboo J. Evaluation of a practical expert defined approach to patient population segmentation: a case study in Singapore. BMC Health Serv Res. 2017;17(1):771

42. Krieger J, Higgins DL. Housing and health: time again for public health action. Am J Public Health. 2002;92(5):758-68.

43. Cohen S, Janicki-Deverts D, Miller GE. Psychological stress and disease. Jama. 2007;298(14):1685-7.

44. Cohen S, Wills TA. Stress, social support, and the buffering hypothesis. Psychol Bull. 1985;98(2):310.
Ready to submit your research? Choose BMC and benefit from:

- fast, convenient online submission

- thorough peer review by experienced researchers in your field

- rapid publication on acceptance

- support for research data, including large and complex data types

- gold Open Access which fosters wider collaboration and increased citations

- maximum visibility for your research: over $100 \mathrm{M}$ website views per year

At $\mathrm{BMC}$, research is always in progress.

Learn more biomedcentral.com/submissions 